\title{
Women In Information Technology: New Connections In The Internet-Based Enterprise
}

Donald J. Caputo, (E-mail: caputo@rmu.edu), Robert Morris University Frederick J. Kohun, (E-mail: kohun@rmu.edu), Robert Morris University

\begin{abstract}
This study first examines the factors that have resulted in the perceived inequality of opportunity for women in the Information Technology disciplines at the collegiate and corporate levels. The corporate continuum is analyzed to determine what specific strategies, if any, are employed to capitalize on the resources of women in the Information Technology spectrum. Implied barriers to the acceptance, integration, development and advancement of women are brought into focus. The article transitions to a review of collegiate innovations in the curriculum that attempt to find solutions that integrate and link corporate needs to university programs, both at the undergraduate and doctoral levels. Corporations ranging in size from small entrepreneurial entities to large multi-national firms, with various degrees of dependence on Internet technology, are surveyed in relation to their utilization of the female technology professional. The qualities, strengths, and holistic skills of the gender in relation to the electronic business spectrum are documented.
\end{abstract}

\subsection{Introduction}

$\mathrm{n}$ the past decade, the emergence of the digital firm with an underlying technological infrastructure has transformed the organization, management and efficiency of the international corporate enterprise. The Internet has surfaced as the key-enabling factor in the global fusion of technology. Not surprisingly, the demand for highly skilled knowledge workers with broad-based business acumen, increased communication skills and an adaptability to the new demands of the customer-driven e-commerce paradigm, has increased dramatically. In fact, the Information Technology Association of America estimates the number of I.T. jobs that are languishing at 840,000 (1). U.S. Government statistics show that women comprise approximately $50 \%$ of the total work force, but just $29 \%$ of the Information Sciences work force (2). Additionally, women drop out of the I.T. field at twice the rate of men (3). Even more telling is the fact that the percentage of women majoring in the computer disciplines in colleges and universities across the country has declined from a high of $37 \%$ in 1986 to a low today of $28 \%$ (3). There is much evidence that women experience a cumulative disadvantage, in computer terms, that begins in the grade schools and continues through the college experience, where it often leads to disinterest and drop-out (4). Computer Science is the only field in which women's participation has decreased over time. Interestingly, a re-emergence of this shrinking gender resource may be catalyzed by the rapid proliferation of the Internet-based enterprise.

\subsection{The Robert Morris University Program}

The starting point of the study is the Robert Morris University Undergraduate program, since it involves the largest number of students over the longest period of time. The strategies developed at Robert Morris to enroll, retain and integrate women students into the computer technology program originated as an open-ended and ongoing plan to enroll and retain all students (not specifically females) in the computer information systems major.

Readers with comments or questions are encouraged to contact the authors via email. 
The first element, and nucleus of the program took the form of a far-reaching and expansive curricular innovation. A narrow computer programming discipline was replaced by a track system that was more responsive to student needs, yet dove-tailed cleanly into the escalating corporate demand for specialty skills. Students would normally enter on the open track, which would allow time to ponder the relative merits of each specialty. Five tracks are available to the student:

$\begin{array}{ll}- & \text { Computer Information Systems } \\ - & \text { Health Care Information Systems } \\ - & \text { Network Administration } \\ - & \text { Accounting Information Systems } \\ \text { - } & \text { Office Information Systems }\end{array}$

The five-track option quickly became the catalyst for the entire program. Previously, students who were unhappy with the narrowly defined major had but two choices: drop out of college or transfer to a new major. With the introduction of the track system, students could concentrate on the specific niche within the discipline that energized and rekindled the learning process. While the rate of retention increased for both men and women students since the program took hold in the fall of 1993, the retention rate for women advanced from $60.11 \%$ to $79.35 \%$ by 1997 . The corresponding data for men show an advance from $69 \%$ to $83 \%$ over the same time frame. Thus, the retention improvement factor for women was $32 \%$, while the male factor improved by $20 \%$. The rationale, as voiced by the women students, was that health care, accounting and office information systems were traditional areas of female interest and aspiration, but still solidly grounded in the computing sciences. Moreover, the programming and networking tracks were not abandoned by women majors, but were no longer the predominant choices.

The rapid growth of the Robert Morris computer systems department from less than 400 students in 1991 to 915 students in 1998, while somewhat a reflection of the steady rise in the vitality and prominence of the computing marketplace, is also a result of innovative collegiate policies.

\subsection{Corporate Strategies}

Pittsburgh, as the fifth largest U.S. commercial software center in the United States, would seem to be an ideal city for the rapid assimilation of women into the computing field. A small-city ambience, combined with a low cost-ofliving ratio, a lessened incidence of crime and highly concentrated health-care and research facilities are advantages that seem to indicate equality in cyberspace. There is some encouragement in the fact that $36 \%$ of computer science workers in the area are women (5). This is marginally better than the national average.

A survey of 47 corporations in the Pittsburgh metropolitan area has attempted to determine the corporate response to the recruitment, retention and promotion of women in the Information Sciences. These corporations and institutions range from large multi-national corporations to health-care institutions, government facilities and small businesses. Specifically, the following questions have been posed:

- What specific strategies are employed by corporations to capitalize on the resources provided by women in Information Technology?

- $\quad$ Has the "glass ceiling" been shattered at the middle and upper levels of the corporate technology world?

- What are the three specific barriers, according to highly placed Information Technology managers, that are most often raised to suggest the reason for the absence (if such absence exists) of women at the highest levels of Information Technology?

However, according to the University of Pittsburgh Center for Social and Urban Research 6th Annual Report, women with college degrees in the area earn less than $50 \%$ of the wages of their male counterparts, and were $50 \%$ less likely than men to be employed in executive or managerial capacities (6). This would not indicate optimum usage of women's potential. Would professional women in the Information Technology field descend to these dismal levels? 
Most corporate managers of information technology, both male and female, have suggested various reasons for unequal treatment of male and female technology workers. Few believe that a formal "glass ceiling" exists. Those who grudgingly speculated on that possibility suggested that it is a surmountable obstacle, not an immovable object.

In fact, the U.S. Department of Labor, in conducting discrimination reviews since 1992 in the Pittsburgh (MidAtlantic) area, has verified that nearly $40 \%$ of reviewed corporations have been identified as non-compliant practitioners of subtle practices that discriminate against women. The most recent finding resulted in significant financial penalties levied against a large corporation in the Pittsburgh area that is one of the 47 companies included in this survey (7).

The corporate failings most often noted by female IT employees were the dearth of female role models, the lack of respect and consideration by fellow employees, and the refusal of managers to recognize the people-oriented skills of the IT women (1).

The most difficult task of this study was to determine what, if any, strategies existed to retain and promote women. Nearly every manager felt that the corporation had in place a number of initiatives to further the careers of women. It was felt that mentoring, for example, was always available to the Information Technology employees of the company. Yet, little was known concerning the implementation of the plan, and whether it was available to (and used by) women as well as men. Most managers downplayed its importance to the female aspirant. In fact, most studies have shown that mentoring is arguably the most important factor affecting the female corporate progression. A recent survey by CIO Magazine found that $70 \%$ of upper-level Information Technology women considered that the lack of a mentor was the greatest barrier to corporate advancement (8). The following statistics display the most often-mentioned strategies, and the percentage of companies that employed them in a somewhat structured or formal manner.

Strategies for women in Information Technology:

\begin{tabular}{llc} 
- & Recruitment and retention & $23 \%$ \\
- & Career development & $17 \%$ \\
- & Identification of high-potential women & $47 \%$ \\
- & Mentoring by upper-echelon employees & $6 \%$ \\
- & Providing internal support & $17 \%$ \\
- & Provilishing training programs & $6 \%$ \\
\hline
\end{tabular}

The majority of managers did agree, however, that the relatively smaller number of women with computerrelated degrees, the corporate inflexibility on family issues, and the simple fact that women have not been in the information technology pipeline long enough to become fully integrated into the corporate design for career advancement, were the deciding factors resulting in the less-than-satisfactory use of the female technology resource in the corporate sphere.

Rationale of Information Technology managers:

$\begin{array}{lll}\text { - } & \text { Family/flexibility issues } & 64 \% \\ \text { - } & \text { Not in pipeline long enough } & 55 \% \\ \text { Fewer women with IT degrees } & 19 \%\end{array}$

A critical factor in determining the viability of women at various corporate Information Technology levels is the percentage of workers at the entry and lower managerial level, and the percent at the senior managerial levels. The senior managerial level is considered to range from the technology director through the vice-presidential and CIO levels.

Percentage of women technology workers: 


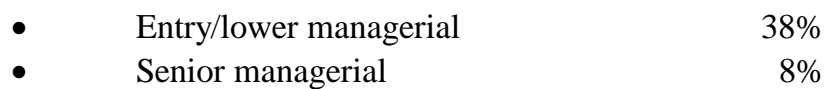

In light of these statistics, it would appear that there is no significant lack of job potential for women at the corporate hiring level. At the upper strata of the Information Technology hierarchy, however, it is apparent that women are in a distinct minority.

\subsection{The Doctoral Program In Information Technology}

The responses of the local corporate community, as well as national statistics, served as input into phases of the doctoral program. As an example, consider that only 18.8 percent of those seeking doctorates in computer science in the United States are women (8). Certainly, this became a program priority issue to be addressed. Because technology allows for mobility and remote accessibility, women are empowered by taking advantage of flexible work schedules, telecommuting facilities and job-sharing. The doctoral program of Robert Morris College attempts to incorporate similar flexibility into its structure.

Enlightened corporations and institutions that are severely impacted by the shortage of information and knowledge workers are rushing headlong into the development of formal mentoring programs. When in place, such programs have resulted in increased employee retention and upward mobility (9). How could this process be integrated into the doctoral program? Would it be as effective for women as for men? Would it produce results as significant as undergraduate program innovations?

The Doctor of Science in Information Systems and Communications (D.Sc.) degree program was debuted in the Fall of 1999. This doctorate was conceived as a professional degree to meet the needs of industry for "specialized generalists" who are capable of performing rigorous applied research and problem solving. Specifically, the program was designed to address the expanding needs of professionals who manage information resources, and solve information, communication and technology-related problems in businesses and other organizations. The program has three distinct characteristics: it is a full-time program in an executive format (three year program with one seven day residency and three weekend residencies in each of the six terms), it is cohort based, and it is interdisciplinary. Of paramount importance to all facets of the program is a distinct overlay of the corporate and education experience. A required endorsement and qualified commitment from the applicant's employer or sponsoring organization merges the educational experience of the students to her/his ongoing professional practice.

After the admission review process was completed, fourteen applicants were admitted. Of these, ten were women. These ten women included three at the CEO level, the Chief Information Officer of a major urban metropolitan police department, a technology section leader of a large international corporation, and two executives in the steel industry. These women were quite special in that they constituted the majority in a technology-based program that was the equivalent of a high-risk venture--a first year program with neither a history nor a reputation.

When the admitted women were informally asked why they were attracted to this program, they all stated the three unique characteristics cited previously: executive format, cohort-based study, and interdisciplinary composition within a team concept. This structure creates a work environment that values people-oriented skills, diversity and team effort, which are generally acknowledged to be prime areas of women's strengths.

During the student's final term, a comprehensive critical technology infusion project will be designed and implemented in conjunction with local corporations and their key information technology managers, who will function as facilitators, consultants and knowledge experts, thus completing the mentoring cycle.

\subsection{The Internet And E-Commerce}


Electronic commerce (e-commerce) is the process of using digital technology as the selected medium for transmitting information between business entities. While it can be implemented using various electronic devices, the Internet has become the prime ingredient in the mix of technologies. The marketing strategies and business models of all entities will necessarily go through a period of change, adaptation and possible re-structuring. E-commerce can be divided into two categories: business-to consumer (B2C) and business-to-business (B2B). IBM Corporation predicts that the combined e-commerce and infrastructure market will reach $\$ 7.5$ trillion early in the $21^{\text {st }}$ century. Whatever the ratio of costs to benefits, it seems assured that the future belongs to those firms that are proactive and "e-centric", with the technical capability to conduct business electronically.

The emergence of the Internet over the last decade has inspired a renewed interest in the technology workplace for women in the computing arena. The number of women using the Internet for all purposes has exceeded the number of men using the medium, according to the nation-wide sample (10). This year, more than $50 \%$ of business travelers will be women. And, of that population, $93 \%$ use the Internet on the road, equaling the male usage rate (11). While women have fallen woefully behind men in the area of advancement to the top levels of the technology-oriented corporations, a recent Annenberg report noted that $13 \%$ of executive positions at Internet-based corporations were held by women. This is an increase of $23 \%$ over tech firms that are not Internet-dependent. Of those female professionals in the general high-tech industry, $46 \%$ telecommute regularly or occasionally, as compared to $44 \%$ of male workers (12).

As previously noted, cultural biases of old-line firms have often shaped stereotypical negative perceptions regarding the leadership abilities of women. Internet companies, due to their relatively recent convergence, for the most part have managed to avoid these biases. As documented in the Klein study (13), the explosive growth of talent-driven Internet- related businesses has opened up leadership opportunities for women. Four interrelated factors are responsible for this event: (a) the demand for qualified top managers; (b) the absence of a "good old boy" network; (c) the existence of diversified, mixed gender personal networks; and (d) an organizational culture open to diversity, which is typical of Internetbased firms. E-commerce is a new game, and the rules of the road are not set in concrete.

Perhaps the most persuasive argument for the connectivity of women in e-commerce is that, by its own nature, the Internet is a network structure, creating a networked organization that will replace the traditional hierarchy structure of past business models. The key question will not be who is in charge, but who has the technical ability, creative vision and relevant business acumen to get the job done. In a network model, there is a broader definition of power and a teamwork (network) ad hoc model is often the most desirable approach to solving the short-term, rapidly evolving nature of tasks within the organization. A number of studies (14) have contrasted the styles and types of work aptitudes of men and women. There seems to be a consensus that the male traits are logical, analytical, top-down, and individualistic in pursuit of goals. Female attributes tend to be creative, teamwork-oriented, holistic and relational in pursuit of goals. The model of the Internet-based entity seems to be particularly adaptable to the resources of women.

In surveying the Southwestern Pennsylvania corporations (basically identical to the previously-surveyed corporations), research was conducted on the basis of the firm's relative size, orientation and method of conducting business. The in-house vs. out-sourced model was noted, and the percentage of employees engaged in the technological areas of the firm was derived. The four categories of corporations included were as follows: (1) small entrepreneurial; (2) sizable with significant e-activity: (3) sizable with minor e-activity; and (4) internet-driven. Sizable firms are defined as those having more than 100 employees.

Approximately $20 \%$ of the firms outsourced their e-commerce activities. The rationale of these corporations was that outsourcing lowered the costs of Information Technology and capital expenses, required less internal staff, and shortened the time to market required. The results of the survey were as follows:

Percentage of women in Information Technology categories:

- $\quad$ Small entrepreneurial firms with significant e-activity 
- Sizable firms with significant e-activity $39 \%$

- Sizable firms with minor e-activity $36 \%$

- Internet-driven firms $46 \%$

The conclusion is that the percentage of women Information Technology professionals tends to increase in relation to the firm's broadening commitment to e-commerce activity.

\section{References}

1. eWeek. (2000 September 11). eBiz Strategies.

2. CIO. (2000 September 1). Why women hate IT.

3. CIO. (2000 September 1). Why women hate IT.

4. Frenkel, Karen (1991 April). Women and computing. Communications of the ACM.

5. $\quad$ Pittsburgh Post Gazette. (1997 September 8). Jobs beckon to women in computer science.

6. University of Pittsburgh Center for Social and Urban Research $6^{\text {th }}$ Annual Report. (1999).

7. Pittsburgh Post Gazette. (1999 September 30). Denying bias, corporation to pay women.

8. CIO On-line Magazine. (1999 September). Self-assessment survey.

9. Information Week. (2000 April 24). IT talent shortage renews interest in mentoring.

10. Bartlett, Michael (2001 June 19). Net users mirror nation's gender breakdown. USA Today.

11. Pennington, April (2002 August). Just take your time. Entrepreneur.

12. Roper Starch Worldwide Report (2001). Women in information technology.

13. Klein, Esther (2001 March). Information technology and women's leadership. NEDSI.

14. Chicago Tribune On-line (2001 June). Women seen thriving in e-commerce. 